\title{
Potencial de clones elite de batata como novas cultivares para Minas Gerais
}

\author{
César ABP Pinto; Alexsandro L Teixeira; Diogo G Neder; Rogério R Araújo; André RO Soares; Guilherme \\ HMR Ribeiro; André L Lepre \\ UFLA-Dep pio $^{\mathrm{to}}$ Biogia, C. Postal 3037, 37200-000 Lavras-MG; cesarbrasil@ufla.br
}

\section{RESUMO}

Historicamente a bataticultura brasileira tem utilizado cultivares desenvolvidas em países de clima temperado, principalmente da Europa, cultivares estas pouco adaptadas às nossas condições ambientais, principalmente ao fotoperíodo mais curto, temperaturas médias mais elevadas, solos mais pobres e maior pressão de patógenos e pragas. Objetivou-se avaliar clones avançados de batata obtidos pelo programa de melhoramento genético da Universidade Federal de Lavras (UFLA), mais resistentes às principais doenças, com ampla adaptação às várias épocas de plantio no sul de Minas Gerais e adequados ao mercado in natura ou ao processamento industrial. Foram realizados seis experimentos em quatro localidades no sul de Minas Gerais, nas safras da seca, de inverno e das águas. O delineamento experimental foi blocos casualizados com 26 tratamentos e três repetições, sendo utilizados 22 clones elites e quatro cultivares como testemunhas. Alguns clones apresentaram características de interesse para serem lançados como novas cultivares, podendo ser destinados aos diversos tipos de mercado. Os clones NES 1-08 e PRM 348 poderiam ser indicados ao mercado in natura, pois apresentaram boa aparência de tubérculos e aptidão para usos múltiplos (fritura, purês, cozimento, etc.). Já os clones CBM 9-10 e CBM 4-48 poderiam ser indicados para o processamento industrial na forma de pré-fritas congeladas, pois apresentaram alto peso específico, alta porcentagem de tubérculos graúdos e formato alongado. Os clones CBM 19-11 e CBM 16-16 poderiam ser indicados para o processamento industrial na forma de "chips" e/ou batata "palha", pois apresentaram formato arredondado e peso específico adequado.

\begin{abstract}
Potential of elite potato clones as new cultivars for Minas Gerais State, Brazil

Potato cropping in Brazil has been using cultivars developed in temperate countries, especially from Europe. These cultivars are not completely adapted to the environmental Brazilian conditions, especially the shorter photoperiod, higher mean temperatures, lower fertility of soils, and higher pressure of pathogens and plagues. The objective of this study was to evaluate elite potato clones from the breeding program of Universidade Federal de Lavras which are more resistant to the most important diseases, with wide adaptation to the various planting seasons in south Minas Gerais State, and destined to the domestic use or industry. Six experiments were carried out in four localities in south Minas Gerais State during the dry, winter, and rainy seasons. The experimental design was randomized complete blocks with three replications 26 treatments ( 22 experimental clones and four control cultivars). Some clones presented desirable traits to be released as new cultivars to attend the various marketing needs. Clones NES 1-08 and PRM 348 could be indicated to the fresh market due to their good general tuber appearance and aptitude to multiple uses (frying, cooking, mashed potatoes) Clones CBM 9-10 and CBM 4-48 could be indicated to the frozen frying industry because of their high specific gravity, high percentage of large tubers and long tuber shape. Clones CBM 19-11 and CBM 16-16 could be indicated to the chip industry or "straw potato" industry, because they present round tubers and adequate specific gravity.
\end{abstract}

Keywords: Solanum tuberosum L., new clones, potato breeding.

Palavras-chave: Solanum tuberosum L., novos clones, melhoramento genético.

\section{(Recebido para publicação em 12 de agosto de 2009; aceito em 31 de agosto de 2010) (Received on August 12, 2009; accepted on August 31, 2010)}

\begin{abstract}
$\mathrm{A}$ maioria das cultivares de batata empregada no Brasil desde a introdução da cultura no país é oriunda de programas de melhoramento desenvolvidos em países de clima temperado, principalmente da Europa. As diferenças entre o Brasil e os países de clima temperado são marcantes, notadamente no que se refere ao fotoperíodo mais curto, temperaturas médias mais elevadas, solos mais pobres e maior pressão de patógenos e pragas. Assim, as cultivares introduzidas não são completamente adaptadas às nossas condições e o melhoramento da batata para as condições brasileiras deve ser conduzido visando a readaptação a fotoperíodos mais curtos e temperaturas
\end{abstract}

mais elevadas, além de necessitarem de maiores níveis de resistência a pragas e doenças (Pinto, 1999).

A temperatura é o principal obstáculo para a produção de batata em regiões tropicais. Por ser uma espécie adaptada ao clima ameno, altas temperaturas, como as observadas em certas safras e regiões do Brasil, acarretam acentuada redução na produção e qualidade de tubérculos, como a redução no teor de matéria seca dos tubérculos e aumento no número de desordens fisiológicas (Haynes \& Haynes, 1983; Menezes et al., 2001). Outro aspecto é com relação ao aumento da incidência de algumas pragas e doenças, como a pinta preta (Alternaria solani), a podridão-mole e canela preta (Erwinia ssp.), e as viroses, sendo neste caso de forma indireta, pois os efeitos da temperatura ocorrem influenciando os seus vetores habituais, como o aumento da população de pulgões (Lopes, 1996; Souza Dias \& Iamauti, 2005).

Outro fator a considerar é o fotoperíodo. A sua duração exerce influência marcante na cultura da batata. Em condições temperadas, o fotoperíodo varia de 16-18 horas de luz, enquanto nas condições tropicais varia de 13-14 horas. Desta forma, com maior tempo de exposição à luz diária nas condições temperadas, ocorre maior produção de fotoassimilados e, consequentemente, maior produção de tubérculos (Pinto \& Benites, 2006). 
Fontes \& Finger (1999) recomendam como condições ideais para o cultivo um ambiente que proporcione maior número de horas de luz e mais dias com temperaturas entre 18 e $23^{\circ} \mathrm{C}$ durante o dia, noites frias com temperaturas em torno de 10 a $16^{\circ} \mathrm{C}$ e o mínimo possível de horas do dia com temperaturas acima de $25^{\circ} \mathrm{C}$. Segundo os mesmos autores, em temperaturas acima de $30^{\circ} \mathrm{C}$ a respiração aumenta rapidamente, o que resulta em decréscimo na fotossíntese líquida e na produção de tubérculos. Temperaturas mais elevadas causam ainda crescimento exuberante da parte aérea, alta respiração e baixa partição de matéria seca para os tubérculos.

Outro aspecto importante é com relação à aparência dos tubérculos, já que no Brasil o principal mercado é in natura. Características como a aparência geral, o formato e tamanho, a cor da pele e polpa dos tubérculos, influenciam a escolha dos consumidores, que consideram estas características associadas à 'qualidade' da batata. Entretanto, a verdadeira qualidade da batata é dada pelo seu valor culinário ou nutricional após cozida ou processada (Dale \& Mackay, 1994). Por diversos fatores o consumo de batata na forma in natura tem reduzido, enquanto o consumo de batata processada industrialmente, na forma de fritura, tem aumentado consideravelmente durante a última década em muitos países (Andreu et al., 2007). O Brasil possui um mercado consumidor potencial para batata processada industrialmente na forma de fritas. Geralmente, a batata na forma pré-frita, é a hortaliça que ocupa o primeiro lugar na pauta das importações pelo Brasil (Aliceweb, 2010), mas, para atender a essa demanda, são necessárias cultivares que satisfaçam a alguns padrões de qualidade. Altos teores de matéria seca, baixas concentrações de açúcares redutores e aparência externa aceitável, como olhos pouco profundos, cor da polpa, tamanho e formato de tubérculos são características desejáveis no processo industrial.

No presente trabalho objetivou-se avaliar clones avançados de batata, mais resistentes às principais doenças, com ampla adaptação às várias épocas de plantio e adequadas ao mercado in natura (mesa) ou ao processamento industrial (pré-fritas congeladas, "chips" e batata "palha").

\section{MATERIAL E MÉTODOS}

Foram avaliados 22 clones elites do Programa de Melhoramento Genético de Batata da Universidade Federal de Lavras (UFLA) (Tabela 1), previamente selecionados para produção, peso específico de tubérculos, tolerância ao calor e resistência a doenças (Martins \& Pinto, 1996; Menezes et al., 2001; Amaro et al., 2003; Lambert et al., 2006; Simon et al., 2009; Benites, 2007). Como testemunhas foram empregadas quatro cultivares (Ágata, Asterix, Atlantic e Monalisa), amplamente utilizadas pelos produtores em Minas Gerais. Foram conduzidos seis experimentos em quatro localidades na região sul de Minas Gerais (Tabela 2). Em Lavras, os experimentos foram plantados na área experimental do Departamento de Biologia da UFLA. Os demais foram realizados em propriedades particulares de produtores tradicionais no cultivo da

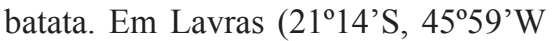
e altitude de 919 m) o clima é caracterizado por temperatura anual média de $19,4^{\circ} \mathrm{C}$, precipitação total anual média de $1.529,7 \mathrm{~mm}$ e umidade relativa do ar média anual de 76,2\% (Brasil, 1992). Em Senador Amaral (22 $35^{\circ}$ 'S, 46 ${ }^{\circ} 11^{\prime} \mathrm{W}$ e altitude de $1.530 \mathrm{~m}$ ) o clima é caracterizado por temperatura anual média de $18,2^{\circ} \mathrm{C}$ e precipitação total anual média de $1.605 \mathrm{~mm}$. Em Camanducaia ( $22^{\circ} 45^{\prime} \mathrm{S}, 56^{\circ} 09^{\prime \prime} \mathrm{W}$ e altitude de 2.057 m) o clima é frio/seco e caracterizado por temperatura anual média de $20,1^{\circ} \mathrm{C}$ e precipitação total anual média de 1.700 mm. Em Munhoz (22 35'S, 46²0'W e altitude de $1.260 \mathrm{~m}$ ) o clima é do tipo mesotérmico úmido com chuvas predominantes no período de outubro a março e temperatura anual média de $19,0^{\circ} \mathrm{C}$ e precipitação total anual média de 1.300 $\mathrm{mm}$. O delineamento experimental foi de blocos casualizados com três repetições e parcelas de quatro linhas de 7,5 metros de comprimento, totalizando 100 plantas por parcela. $\mathrm{O}$ espaçamento foi de $0,3 \times 0,8 \mathrm{~m}$.

O solo foi preparado com aração, gradagem e sulcamento, onde se aplicou $3.000 \mathrm{~kg} \mathrm{ha}^{-1}$ do formulado comercial 4-14-08 (N, $\left.\mathrm{P}_{2} \mathrm{O}_{5}, \mathrm{~K}_{2} \mathrm{O}\right)$. Entre 30 e 40 dias após o plantio foi feita uma adubação de cobertura com sulfato de amônio, sendo utilizados entre 300 a $400 \mathrm{~kg} / \mathrm{ha}$, e efetuada a amontoa. O controle de plantas daninhas, insetos pragas, doenças e demais tratos culturais foram realizados conforme o manejo tradicional para a produção comercial de batata na região. Em Lavras, as irrigações seguiram um turno de rega semanal desde o plantio, sendo suspensas após a dessecação das ramas, dez dias antes da colheita do experimento. Nos demais locais não foram feitas irrigações.

Foram consideradas para análise as características de maior importância para a produção e industrialização dos tubérculos: produção de tubérculos comercializáveis; porcentagem da produtividade de tubérculos graúdos; peso médio de tubérculos; peso específico de tubérculos [(PET), estimado por peso no ar/(peso no ar - peso na água)]; aparência externa dos tubérculos $(1=$ ruim a $5=$ ótima), porcentagem de desordens fisiológicas.

No experimento de Senador Amaral (2007) foram analisadas ainda as seguintes características: uniformidade de formato dos tubérculos $(1=$ desuniforme a $5=$ uniforme); vigor da planta $(1=$ pouco vigorosa a $5=$ muito vigorosa); formato dos tubérculos (alongados, ovalados e redondos); cor da polpa; cor do palito frito ( $1=$ amarelo esbranquiçado a $5=$ marrom escuro).

Análises de variância foram efetuadas para todos os caracteres em cada local e posteriormente foi realizada a análise conjunta dos experimentos por meio do procedimento GLM do pacote estatístico (Statistical Analysis System). As análises de estabilidade foram realizadas pelas metodologias de Lin \& Binns (1988) e de Annicchiarico (1992).

\section{RESULTADOS E DISCUSSÃO}

Para a análise conjunta foram considerados apenas 18 clones e duas testemunhas (Atlantic e Monalisa) que participaram de todos os seis experimentos. Atlantic é uma cultivar usada para o processamento na forma de chips, enquanto que Monalisa é empregada como 
Tabela 1. Médias da análise conjunta dos clones e das testemunhas para produção de tubérculos comerciáveis, porcentagem de tubérculos graúdos, peso médio de tubérculo, peso específico, porcentagem de desordens fisiológicas, aparência geral de tubérculos e cor de palitos fritos em seis locais/safras no sul de Minas Gerais, 2007/2008 (averages from the joint analysis for clones and controls for marketable tuber yield, percentage of large tubers, mean tuber weight, tuber specific gravity, percentage of tubers' physiological disorders, general tuber appearance, and color of fried sticks from six localities/seasons in south Minas Gerais State). Lavras, UFLA, 2009.

\begin{tabular}{|c|c|c|c|c|c|c|c|}
\hline Clones & $\begin{array}{l}\text { Produção } \\
\left(\mathrm{t} \mathrm{ha}^{-1}\right)\end{array}$ & $\begin{array}{c}\text { Graúdos } \\
(\%)\end{array}$ & $\begin{array}{l}\text { Peso médio } \\
\text { tubérculos (g) }\end{array}$ & $\begin{array}{c}\text { Peso } \\
\text { específico }\end{array}$ & $\begin{array}{c}\text { Desordens } \\
\text { fisiológicas (\%) }\end{array}$ & Aparência & $\begin{array}{c}\text { Cor } \\
\text { palitos }\end{array}$ \\
\hline BarakaxChiquita & $21,9 b^{1}$ & $48,1 \mathrm{~b}$ & $80,7 \mathrm{~b}$ & $1,0798 \mathrm{~b}$ & $4,01 \mathrm{a}$ & $3,04 \mathrm{a}$ & 3,0 \\
\hline CBM 16-16 & $28,4 \mathrm{a}$ & $66,2 \mathrm{a}$ & $85,2 \mathrm{~b}$ & $1,0781 \mathrm{~b}$ & $0,02 \mathrm{a}$ & $2,98 \mathrm{a}$ & 3,0 \\
\hline CBM 18-11 & $27,9 \mathrm{a}$ & $75,6 \mathrm{a}$ & $99,4 \mathrm{a}$ & $1,0639 \mathrm{~d}$ & $2,08 \mathrm{a}$ & $2,93 \mathrm{a}$ & 1,0 \\
\hline CBM 19-11 & $24,6 \mathrm{a}$ & $51,8 \mathrm{~b}$ & $74,6 \mathrm{~b}$ & $1,0786 \mathrm{~b}$ & $0,14 \mathrm{a}$ & $2,93 \mathrm{a}$ & 1,5 \\
\hline CBM 22-19 & $32,1 \mathrm{a}$ & $68,2 \mathrm{a}$ & $87,1 \mathrm{~b}$ & $1,0732 \mathrm{c}$ & $2,00 \mathrm{a}$ & $2,35 \mathrm{~b}$ & 2,5 \\
\hline CBM 4-48 & $31,0 \mathrm{a}$ & $78,1 \mathrm{a}$ & $107,0 \mathrm{a}$ & $1,0794 \mathrm{~b}$ & $0,26 \mathrm{a}$ & $2,86 \mathrm{a}$ & 2,5 \\
\hline CBM 9-10 & $24,9 \mathrm{a}$ & $60,3 \mathrm{a}$ & $86,5 \mathrm{~b}$ & $1,0824 \mathrm{~b}$ & $0,33 \mathrm{a}$ & $2,57 \mathrm{~b}$ & 1,0 \\
\hline ESL 12-36 & $25,6 \mathrm{a}$ & $41,0 \mathrm{~b}$ & $74,8 \mathrm{~b}$ & $1,0694 \mathrm{c}$ & $0,67 \mathrm{a}$ & $2,17 \mathrm{~b}$ & 3,0 \\
\hline ESL 9-04 & $21,6 \mathrm{~b}$ & $64,5 \mathrm{a}$ & $77,8 \mathrm{~b}$ & $1,0781 \mathrm{~b}$ & $2,34 \mathrm{a}$ & $2,15 \mathrm{~b}$ & 1,0 \\
\hline GBA 3-45 & $23,5 \mathrm{~b}$ & $54,1 \mathrm{~b}$ & $81,8 \mathrm{~b}$ & $1,0723 \mathrm{c}$ & $0,58 \mathrm{a}$ & $2,33 \mathrm{~b}$ & 2,5 \\
\hline GSI 1-02 & $25,3 \mathrm{a}$ & $51,1 \mathrm{~b}$ & $78,7 \mathrm{~b}$ & $1,0686 \mathrm{c}$ & $3,95 \mathrm{a}$ & $2,48 \mathrm{~b}$ & 3,0 \\
\hline GSI 5-10* & $31,3 \mathrm{a}$ & $58,6 \mathrm{~b}$ & 74,7 & $1,0723 \mathrm{c}$ & $1,48 \mathrm{a}$ & $3,04 \mathrm{a}$ & 3,5 \\
\hline GSI 8-04* & $34,3 \mathrm{a}$ & - & - & $1,0636 \mathrm{~d}$ & - & - & 4,0 \\
\hline MCR 17-02 & $15,9 \mathrm{~b}$ & $48,1 \mathrm{~b}$ & $70,0 \mathrm{~b}$ & $1,0933 \mathrm{a}$ & $0,36 \mathrm{a}$ & $2,56 \mathrm{~b}$ & 1,5 \\
\hline NES 1-08 & $22,9 \mathrm{~b}$ & $67,5 \mathrm{a}$ & $108,8 \mathrm{a}$ & $1,0776 \mathrm{~b}$ & $0,59 \mathrm{a}$ & $3,80 \mathrm{a}$ & 3,5 \\
\hline NES 2-68 & $24,7 \mathrm{a}$ & $45,2 \mathrm{~b}$ & $75,4 \mathrm{~b}$ & $1,0608 \mathrm{~d}$ & $0,00 \mathrm{a}$ & $3,52 \mathrm{a}$ & 4,0 \\
\hline NES 7-150 & $22,8 \mathrm{~b}$ & $69,1 \mathrm{a}$ & $103,4 \mathrm{a}$ & $1,0679 \mathrm{c}$ & $0,02 \mathrm{a}$ & $3,34 \mathrm{a}$ & 3,5 \\
\hline PRM 348 & $28,7 \mathrm{a}$ & $62,4 \mathrm{a}$ & $89,8 \mathrm{~b}$ & $1,0750 \mathrm{~b}$ & $1,00 \mathrm{a}$ & $2,86 \mathrm{a}$ & 3,0 \\
\hline PRM 37 & $18,9 \mathrm{~b}$ & 47,7 & 67,5 & $1,0678 \mathrm{c}$ & - & $1,94 \mathrm{~b}$ & 4,5 \\
\hline PRM 444 & $19,0 \mathrm{~b}$ & $48,9 \mathrm{~b}$ & $93,2 \mathrm{a}$ & $1,0684 \mathrm{c}$ & $1,60 \mathrm{a}$ & $2,50 \mathrm{~b}$ & 4,5 \\
\hline PRM 490* & $12,5 \mathrm{~b}$ & $24,2 \mathrm{~b}$ & $69,0 \mathrm{~b}$ & $1,0713 \mathrm{c}$ & $3,14 \mathrm{a}$ & $2,95 \mathrm{a}$ & 2,0 \\
\hline PRM 510* & $11,4 \mathrm{~b}$ & - & 79,4 & $1,0720 \mathrm{c}$ & $0,18 \mathrm{a}$ & - & 4,5 \\
\hline Ágata* & $15,8 \mathrm{~b}$ & $39,3 \mathrm{~b}$ & $76,8 \mathrm{~b}$ & $1,0560 \mathrm{~d}$ & $1,36 \mathrm{a}$ & $3,25 \mathrm{a}$ & 1,5 \\
\hline Asterix* & $18,4 \mathrm{~b}$ & 59,5 & 100,4 & $1,0729 \mathrm{c}$ & - & $2,96 \mathrm{a}$ & 3,0 \\
\hline Atlantic & $29,2 \mathrm{a}$ & $62,6 \mathrm{a}$ & $77,8 \mathrm{~b}$ & $1,0749 \mathrm{~b}$ & $4,55 \mathrm{a}$ & $2,15 \mathrm{~b}$ & 2,0 \\
\hline Monalisa & $20,8 \mathrm{~b}$ & $57,4 \mathrm{~b}$ & $88,3 \mathrm{~b}$ & $1,0636 \mathrm{~d}$ & $2,17 \mathrm{a}$ & $3,36 \mathrm{a}$ & 4,0 \\
\hline Média & 23,6 & 56,2 & 84,3 & 1,07 & 1,43 & 2,79 & 2,8 \\
\hline $\mathrm{CV}(\%)$ & 19,50 & 19,82 & 14,73 & 0,48 & 210,64 & 17,53 & - \\
\hline
\end{tabular}

${ }^{1}$ Scott Knot 5\%, *médias de três locais. (Scott Knot 5\%, *averages from three localities).

cultivar de mesa. Os clones experimentais já foram avaliados em vários anos e locais, apresentando características de interesse para serem lançados como novas cultivares.

Todos os caracteres avaliados apresentaram diferenças significativas entre clones e entre locais, evidenciando a variabilidade existente entre os genótipos e a diversidade dos locais/safras. Diversos clones experimentais apresentaram comportamento superior para o conjunto de caracteres (Tabela 1) e, portanto, têm potencial para serem lançados como novas cultivares. Para o uso domésti- co (mesa) são requeridos clones com aptidão múltipla e boa aparência dos tubérculos. Dentre esses, o clone PRM 348 foi bem produtivo, com alta porcentagem de tubérculos graúdos, formato ovalado e aparência de tubérculos estatisticamente igual às cultivares Ágata e Monalisa. Seu peso específico é superior a Asterix e a cor dos palitos fritos foi desejável, indicando a sua boa qualidade para a fritura (Tabela 1). Este clone apresentou ainda, resistência à pinta preta (Martins \& Pinto, 1996) e podridão mole (Assis, 2007). Outros clones para o uso doméstico são os denominados
NES. De maneira geral, apresentaram boa aparência, sendo os clones NES 1-08 e NES 2-68 estatisticamente iguais às cultivares Ágata e Monalisa nesse quesito. Suas produtividades foram semelhantes às de Monalisa e Ágata, com exceção do clone NES 7-150, que apresentou produtividade superior a Ágata, Asterix e Monalisa. O clone NES 1-08 apresentou peso específico de 1,0776 o que indica sua ótima qualidade para a fritura. Essa característica é uma vantagem desse clone em relação às cultivares de mesa atualmente em uso no Brasil, que normalmente possuem 
Tabela 2. Locais, períodos e safras de seis experimentos conduzidos na região sul de Minas Gerais (local, time and crop season of six experiments carried out in the south Minas Gerais State). Lavras, UFLA, 2009.

\begin{tabular}{lccc}
\hline Experimento & Local & Período & Safra/Ano \\
\hline 1 & Lavras & Abril a Agosto & Inverno/2006 \\
2 & Senador Amaral & Fevereiro a Junho & Seca/2007 \\
3 & Lavras & Maio a Agosto & Inverno/2007 \\
4 & Camanducaia & Novembro a Maio & Águas $/ 2007-08$ \\
5 & Senador Amaral & Novembro a Maio & Águas/2007-08 \\
6 & Munhoz & Novembro a Maio & Águas/2007-08 \\
\hline
\end{tabular}

Tabela 3. Análise de estabilidade para produção de tubérculos pelos métodos de Lin e Binns (1988) e de Annicchiarico (1992) considerando 18 clones experimentais e duas cultivares testemunhas, em seis locais/safras no sul de Minas Gerais (stability analysis for tuber yield by the Lin \& Binns (1988) and the Annicchiarico (1992) methods considering 18 experimental clones and two cultivars in six localities/seasons in south Minas Gerais State). Lavras, UFLA, 2009.

\begin{tabular}{|c|c|c|c|}
\hline \multirow{2}{*}{ Clones } & \multicolumn{2}{|c|}{ Lin \& Binns } & \multirow{2}{*}{$\begin{array}{c}\text { Annicchiarico } \\
\text { I(i) }\end{array}$} \\
\hline & $\mathbf{P}(\mathbf{i})$ & (\% interação) & \\
\hline Baraka x Chiquita & $178.715,64$ & 2,67 & 61,27 \\
\hline CBM 16-16 & $51.948,03$ & 1,33 & 71,97 \\
\hline CBM 18-11 & $75.755,06$ & 4,06 & 81,06 \\
\hline CBM 19-11 & $134.508,37$ & 5,04 & 59,61 \\
\hline CBM 22-19 & $23.212,14$ & 2,12 & 97,96 \\
\hline CBM 4-48 & $24.562,44$ & 1,03 & 106,20 \\
\hline CBM 9-10 & $119.097,41$ & 3,51 & 55,60 \\
\hline ESL 12-36 & $114.826,27$ & 4,91 & 81,89 \\
\hline ESL 9-04 & $213.543,79$ & 7,62 & 61,84 \\
\hline GBA 3-45 & $171.208,02$ & 7,50 & 40,34 \\
\hline GSI 1-02 & $104.651,37$ & 2,26 & 68,70 \\
\hline MCR 17-02 & $382.992,76$ & 8,16 & 21,03 \\
\hline NES 1-08 & $188.715,89$ & 8,27 & 59,68 \\
\hline NES 2-68 & $150.250,85$ & 7,88 & 69,58 \\
\hline NES 7-150 & $167.832,04$ & 4,54 & 74,71 \\
\hline PRM 348 & $55.617,27$ & 2,45 & 74,81 \\
\hline PRM 444 & $288.466,84$ & 8,40 & 60,06 \\
\hline PRM 490 & $518.838,31$ & 9,88 & 33,43 \\
\hline Atlantic & $55.916,43$ & 3,45 & 81,58 \\
\hline Monalisa & $217.024,03$ & 4,91 & 73,08 \\
\hline
\end{tabular}

baixo peso específico dos tubérculos e baixa aptidão para a fritura.

O clone CBM 19-11 apresentou formato arredondado, peso específico pouco superior à Atlantic, mas estatisticamente iguais, e cor dos palitos fritos bem clara (Tabela 1). Esse clone poderia se destinar à indústria de chips e/ou palha, entretanto, apresentou baixa porcentagem de tubérculos graúdos. $\mathrm{O}$ clone CBM 16-16 é altamente produtivo específico pouco inferior à Atlantic, podendo se destinar à indústria de batata palha, pois apresenta cor dos palitos fritos desejável (coloração ouro). A sua utilização para outros fins fica comprometida pela falta de uniformidade no formato dos tubérculos, inviabilizando seu emprego na indústria de chips, que requer formato redondo uniforme.

Os clones CBM 4-48 e CBM 9-10, ambos de formato alongado, apresentaram pesos específicos de 1,0794 e 1,0824, respectivamente, ligeiramente superiores à Atlantic, cor dos palitos fritos aceitável e alta produtividade de tubérculos comercializáveis. Esses clones poderiam ser recomendados para a indústria de pré-fritas congeladas, cujo mercado não dispõe de cultivares específicas para tal uso. Como cultivares destinadas ao consumo in natura eles não seriam indicados, pois apresentam como desvantagem aparência de tubérculos inferior às cultivares Ágata e Monalisa, além do clone CBM 9-10 possuir peso específico muito elevado, o que o tornaria impróprio para o cozimento e preparo de purês. Uma vantagem adicional desse último clone é a sua maior resistência à podridão mole, causada por Erwinia carotovora (Assis, 2007).

A interação clones $\mathrm{x}$ locais foi significativa para a maioria dos caracteres, exceto para peso específico de tubérculos, porcentagem de desordens fisiológicas e vigor vegetativo. Esses resultados indicam que determinados clones foram superiores em certos locais/safras, mas não apresentaram o mesmo comportamento em outros ambientes.

Considerando o índice de Lin \& Binns, os clones mais estáveis foram CBM 22-19, CBM 4-48, CBM 16-16, PRM 348 e a cultivar Atlantic (Tabela 3). Para o índice de Annicchiarico destacaram-se os clones CBM 4-48, CBM 22-19, ESL 12-36, Atlantic, CBM 18-11 e PRM 348. Os clones CBM 1616 e CBM 22-19 também apresentaram alta estabilidade quando avaliados em condições de temperaturas elevadas (condições desfavoráveis) e condições mais satisfatórias (temperaturas amenas) num total de nove ambientes (Lambert et al., 2006). Essa maior estabilidade dos clones revela que seus comportamentos são mais previsíveis e que esses clones 


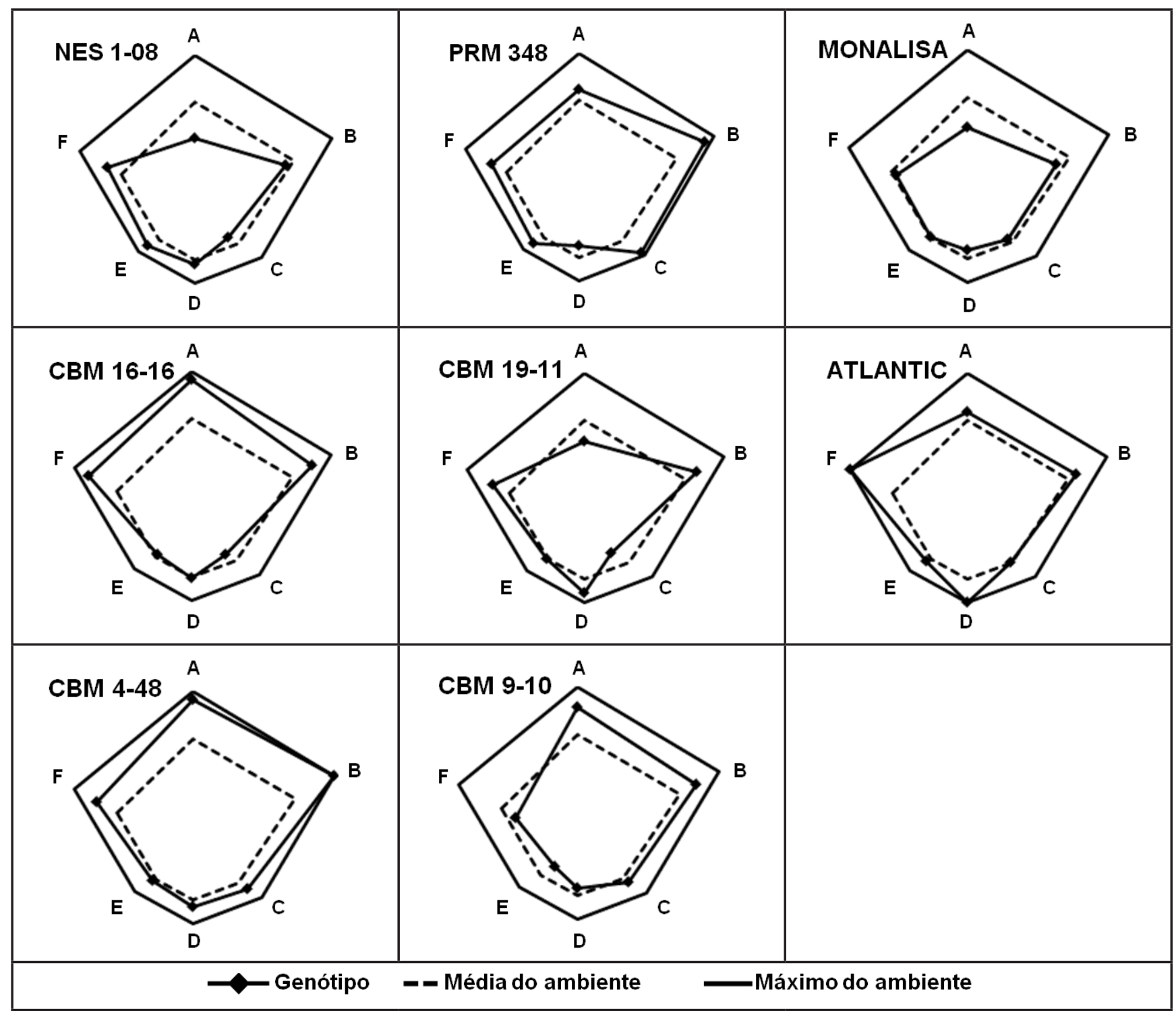

Figura 1. Comportamento médio dos melhores clones para produtividade de tubérculos em seis experimentos conduzidos em Lavras-2006 (A), Senador Amaral-2007 (B), Lavras-2007 (C), Camanducaia-2007/08 (D), Senador Amaral-2007/08 (E), e Munhoz 2007/08 (F) (average behavior of the best clones for tuber yield in six experiments carried out in Lavras-2006 (A), Senador Amaral-2007 (B), Lavras-2007 (C), Camanducaia-2007/08 (D), Senador Amaral-2007/08 (E), and Munhoz 2007/08 (F)). Lavras, UFLA, 2009.

sofrem menos os impactos negativos dos ambientes, assegurando-lhes melhores produtividades em uma gama mais ampla de ambientes.

A Figura 1 mostra as produtividades de tubérculos de alguns clones em relação à produtividade média e máxima nos seis locais de avaliação. Para os clones com aptidão para mesa, observa-se que o clone PRM 348 foi superior à média em cinco locais, exceto em Camanducaia. O clone NES 1-08, embora não tenha apresentado média alta, não diferiu estatisticamente da cultivar Monalisa, cuja produtividade ficou abaixo da média na maioria dos ambientes. Considerando a aptidão para a indústria de chips/palha, a cultivar Atlantic superou a produtividade média em quase todos os ambientes. O clone CBM 16-16 apresentou produtividades próximas do máximo nos locais com maiores produtividades (Lavras, 2006; Senador Amaral, 2007 e Munhoz, 2007/08) e produtividades médias nos ambientes menos favoráveis (Lavras, 2007; Camanducaia, 2007/08 e Senador Amaral 2007/08). Já o clone CBM 19-11 se situou próximo da média na maioria dos ambientes. O clone CBM 4-48, que apresenta aptidão para a indústria de pré-fritas congeladas, teve um desempenho superior à média em todos os ambientes e ainda demonstrou alta produtividade nos ambientes mais favoráveis (Figura 1).

A Figura 2 apresenta o desempenho médio dos melhores clones nos seis ambientes para os caracteres de interesse para o consumo doméstico. Para cada caráter é apresentado o desempenho do clone (ou cultivar) em relação ao desempenho médio e máximo do referido caráter. Os clones PRM 348 e NES 1-08 superaram as cultivares tradicionais Ágata e Monalisa para a maioria dos caracteres, demonstrando, mais uma vez seu potencial para o mercado de mesa. A Figura 3 mostra o comportamento dos 


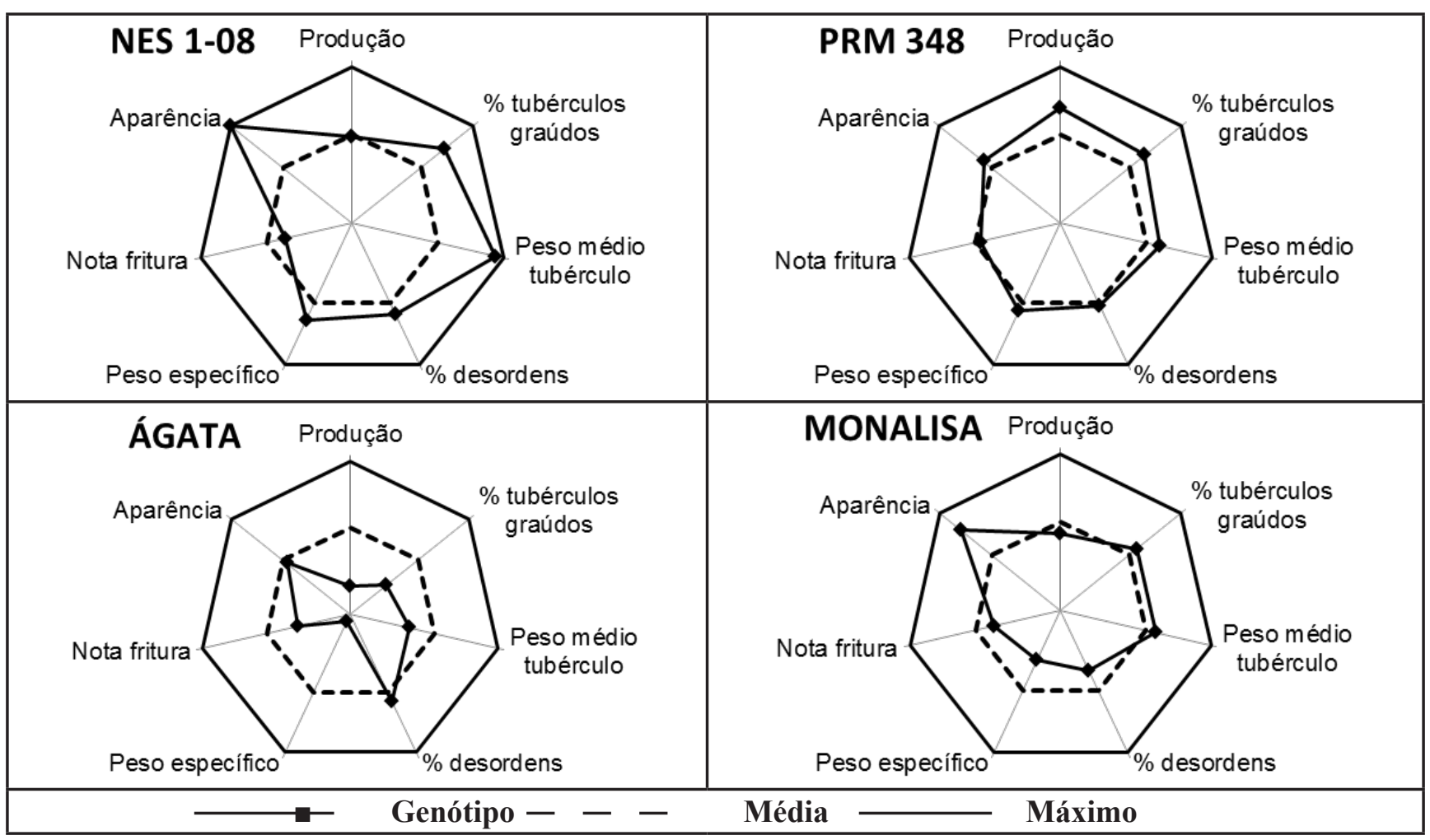

Figura 2. Comportamento médio dos melhores clones com aptidão para mesa para caracteres dos tubérculos: produção, porcentagem de graúdos, peso médio, peso específico, porcentagem de desordens fisiológicas, fritura e aparência em seis experimentos conduzidos na região sul de Minas Gerais durante dois anos e três safras (average behavior of the best clones with aptitude to the fresh market concerning tuber traits: yield, percentage of large tubers, tuber mean weight, specific gravity, percentage of tubers' physiological disorders, frying score and general appearance in six experiments carried out in south of Minas Gerais State, during two years and three growing seasons). Lavras, UFLA, 2009.

clones com potencial para a indústria relativo aos caracteres de interesse. Os clones indicados para a indústria de chips/palha (CBM 16-16 e CBM 19-11) superaram a média para quase todos os caracteres e se mostraram superiores à cultivar Atlantic em vários caracteres. Já os clones CBM 4-48 e CBM 9-10, indicados para a indústria de pré-fritas apresentaram comportamento superior à média para todos os caracteres e até mesmo desempenho máximo para a porcentagem de tubérculos graúdos e peso médio de tubérculos (CBM 4-48) e nota de fritura (CBM 9-10). Esses clones superaram a cultivar Asterix que tem sido usada esporadicamente como material para a produção de pré-fritas.

Finalmente, resta comentar que todos os clones experimentais aqui citados já foram avaliados em mais de quinze experimentos de campo e se encontram infectados com alguma virose (PLRV e/ou PVY e/ou PVX e/ou PVS). As viroses representam um problema grave à bataticultura, pois são transmitidas por insetos vetores e translocam-se para a batata semente, podendo reduzir a produtividade de tubérculos em 10 a 80\% (Figueira, 1999). Além disso, geralmente os tubérculos produzidos são de menor tamanho. A sua disseminação adquire grandes dimensões no Brasil, pois as condições climáticas favorecem a ocorrência de altas populações de insetos vetores de vírus durante todo o ano (Gallo, 1988). Isto faz com que, após algumas multiplicações no campo, a porcentagem de plantas infectadas atinja níveis preocupantes. Andrade \& Figueira (1991) verificaram na região sul de Minas Gerais que apenas três multiplicações no campo foram suficientes para elevar a taxa de infecção do vírus do enrolamento das folhas da batata (PLRV) e do vírus Y da batata (PVY) a mais de $90 \%$. É possível que a limpeza viral dos clones experimentais avaliados neste trabalho, possa contribuir com o aumento da produtividade, realçando ainda mais, a sua superioridade em relação às cultivares comerciais. Essa limpeza viral já está ocorrendo no Laboratório de Cultura de Tecidos da UFLA.

\section{AGRADECIMENTOS}

À FAPEMIG pelo apoio financeiro e ao CNPq por bolsa de produtividade em pesquisa e bolsas de pós-graduação.

\section{REFERÊNCIAS}

ALICEWEB. http://aliceweb.desenvolvimento. gov.br, acessado em 16/10/2010.

AMARO GB; PINTO CABP; MARTINS NETO CL; LAMBERT ES. 2003. Seleção precoce de clones de batata para caracteres dos tubérculos. Ciência e Agrotecnologia 27: 585-589.

ANDRADE ER; FIGUEIRA AR. 1991. Degenerescência em seis cultivares de batata (Solanum tuberosum L.) na região Sul de Minas Gerais. Ciência e Prática 15: 9-15.

ANDREU MA; PINTO CABP; SIMON GA. 2007. Genetic markers for processing traits in potato. Crop Breeding and Applied Biotechnology 7: 67-73.

ASSIS JC. 2007. Resistência de clones de batata à podridão-mole (Erwinia carotovora subsp. carotovora). Lavras: UFLA. 51p. (Tese 


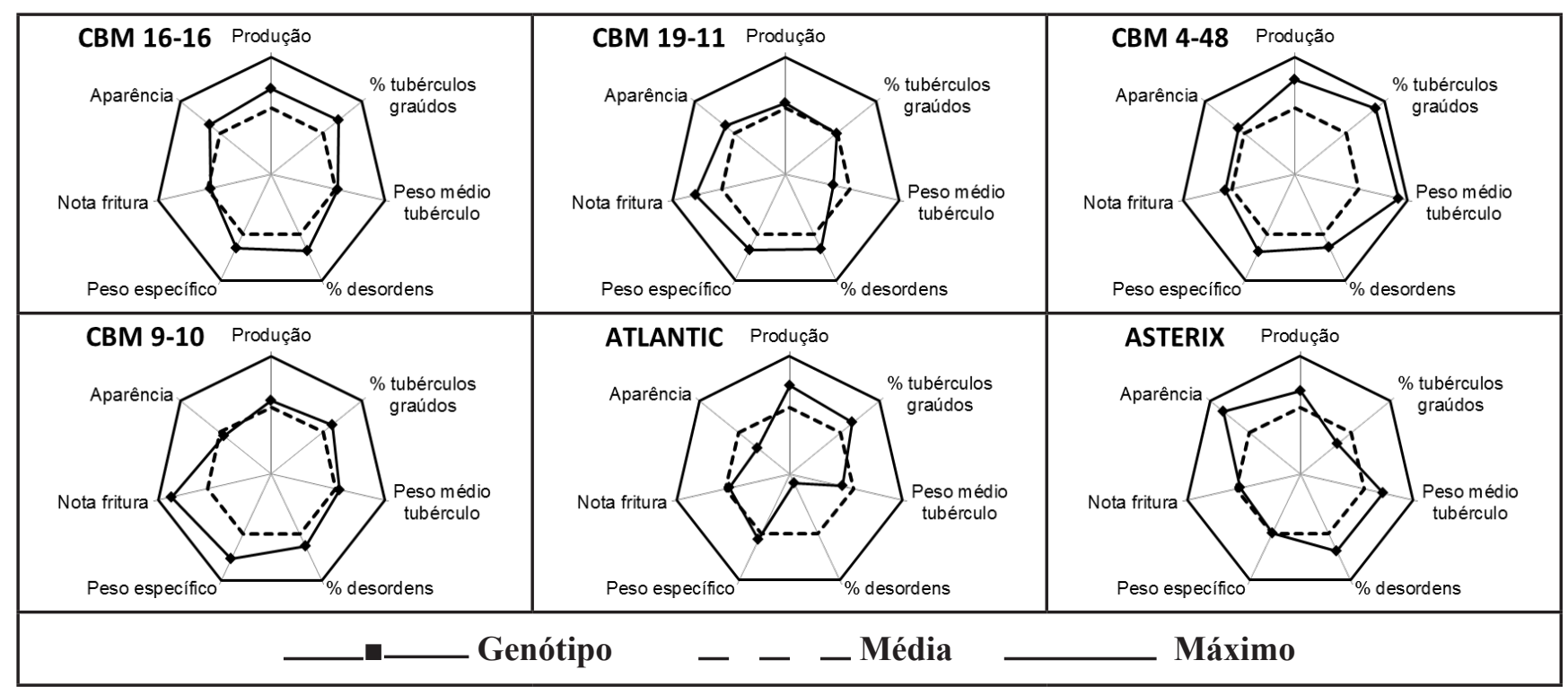

Figura 3. Comportamento médio dos melhores clones com aptidão para indústria para caracteres dos tubérculos: produção, porcentagem de graúdos, peso médio, peso específico, porcentagem de desordens fisiológicas, fritura e aparência de tubérculos em seis experimentos conduzidos na região sul de Minas Gerais durante dois anos e três safras (average behavior of the best clones with aptitude to the industry concerning tuber traits: yield, percentage of large tubers, tuber mean weight, specific gravity, percentage of tubers' physiological disorders, frying score and general appearance in six experiments carried out in south of Minas Gerais State, during two years and three growing seasons). Lavras, UFLA, 2009.

mestrado).

BENITES FRG. 2007. Seleção recorrente em batata visando tolerância ao calor. Lavras: UFLA. 90p. (Tese doutorado).

DALE MFB; MACKAY GR. 1994. Inheritance of table and processing quality. In: MACKAY GR; BRADSHAW JE. Potato genetics. Cambridge: CAB International, p. 285-315.

FIGUEIRAAR. 1999. Viroses da Batata: Situação Atual e Perspectivas Futuras. Informe Agropecuário 20: 86-96.

FONTES PCR; FINGER FL. 1999. Dormência dos tubérculos, crescimento da parte aérea e tuberização da batateira. Informe Agropecuário 20: 24-29.

GALLO D. Manual de entomologia agrícola . 2.ed. São Paulo: Ceres, 1988. 649p.

HAYNES KG; HAYNES FL. 1983. Stability of high specific gravity genotypes of potatoes under high temperatures. Americam Potato Journal 60: 17-26.

LAMBERT ES; PINTO CABP; MENEZES CB. 2006. Potato improvement for tropical conditions. I: Analysis of stability. Crop Breeding and Applied Biotechnology 6: 129-135.

LOPES CA. 1996. Doenças causadas por bactérias em batata. Informe Agropecuário 18: 36-40.

MARTINS PR; PINTO CABP. 1996. Capacidade de combinação de genótipos de batata para resistência a pinta preta, produtividade e peso específico de tubérculos. Horticultura Brasileira 14: 161-169.

MENEZES CB; PINTO CABP; LAMBERT ES. 2001. Selection of potato clones for cool and warm seasons in Brazil. Crop Breeding and Applied Biotechnology 1: 145-157.

PINTO CABP; BENITES FRG. 2006.
Melhoramento da batata para condições tropicais. In: SIMPÓSIO SOBRE ATUALIZAÇÃO EM GENÉTICA E MELHORMENTO DE PLANTAS. Melhoramento de plantas visando a tolerância a estresses abióticos, 10., 2006, Lavras. Anais... Lavras: UFLA, p. 58-77.

PINTO CABP. 1999. Melhoramento Genético da batata. Informe Agropecuário 20: 120-128.

SIMON GA; PINTO CABP; BENITES FRG. 2009. Seleção de famílias clonais de batata em diferentes ambientes. Ciência e Agrotecnologia 33: 164-169.

SOUZA-DIAS JAC; IAMAUTI MT. 2005. Doenças da batateira (Solanum tuberosum L.). In: Kimati H; Amorin L; Rezende JAM; Bergamin-Filho A; Camargo LEA.(eds). Manual de Fitopatologia p. 119-142. 